\title{
Enzymes and histological differentiation of tumours
}

\author{
C. C. BIRD \\ From the Department of Pathology, University of Edinburgh
}

The study of enzymes in tumours has been one of the central themes of cancer research for many years. This interest stems from the early discoveries of Warburg (1930) that many kinds of tumours appear to have a specific form of metabolism. Since the ultimate control of metabolism in tissues depends upon the levels of enzyme activity, it was logical to search for possible changes in tumour enzyme content as the primary cause of the alteration in tumour metabolism. A vast literature now exists on the enzymology of many kinds of spontaneous and transplantable tumours of animals (particularly rodents) and of man (Greenstein, 1954; Greenstein, 1956; Aisenberg, 1961; Busch and Starbuck, 1964; Pitot, 1966; Knox, 1967; Shonk and Boxer, 1967; Wenner, 1967). One of the most frequently observed differences between a tumour and its homologous normal tissue has been the reduction or loss of enzyme activity or of the responsiveness of an enzyme to its normal regulatory mechanisms. Demonstration of the loss of enzymes and other proteins in tumours led to formulation of the deletion hypothesis of cancer (Miller and Miller, 1947; Potter, 1958) although this concept can no longer be considered tenable.

However, until recently, despite this intensive interest in tumour enzyme activity, it has been difficult to relate the significance of any enzyme changes demonstrated to the histological differentiation of tumours. The principal cause of this has been that in most previous studies efforts were largely directed towards establishing differences in selected enzyme activity between fully established tumours and their homologous normal tissues. Thus, tumours at one stage of histological development only were examined in most cases and any possible differences in enzyme content which might be related to structural variations within a single histogenetic tumour class were not considered. Furthermore, in many studies the choice of enzymes examined was determined on a more or less random rather than on a systematic basis. Sometimes it reflected attempts to establish possible differences in activity of enzymes for diagnostic purposes. More commonly, however, it depended upon the special interests and expertise of the individual investigator or was determined by the reliability of the available analytical methods at the time. Therefore, until fairly recently, any meaningful correlation of enzyme activity with the structural differentiation of tumours has virtually been impossible.

However, in the past several years emphasis has shifted towards a more systematic analysis of related groups of enzymes in histologically graded series of tumours derived from a single organ or tissue. The concentration upon tumours of a single homogeneous cell type, which show varying degrees of histological differentiation, is based on the assumption that tumours most closely resembling their homologous normal tissues of origin are most likely to show the deviation from normal which has the greatest relevance to neoplasia (Farber, 1968).

The most thoroughly studied tumour system developed to exploit this concept has been derived from the rat liver. In this paper the results of some of these studies will be used to illustrate how the pattern of enzyme and metabolic activity in hepatomas can be related to the extent of their structural differentiation. The implications of these findings for current understanding of the fundamental metabolic changes associated with neoplasia will be discussed.

\section{Rat Hepatoma System}

Primary hepatocellular carcinomas can be induced in rats by prolonged feeding for several months with certain carcinogenic aromatic amines. By serial transplantation of some of these tumours in inbred strains of rat a graded system of tumours has been developed in which there is a clear spectrum of histological differentiation and growth rate (Morris, 1963, 1965; Morris and Wagner, 1968). At one extreme of this spectrum tumours are well differentiated, closely resemble the liver histologically, and sometimes retain the ability to synthesize bile. These tumours show few mitoses and are slow growing and include the 'minimal deviation' hepatomas. At 
the other end of the spectrum tumours are poorly differentiated, show varying anaplastic features, and have minimal histological resemblances to normal liver. Such tumours, which are rapidly growing, exhibit frequent mitoses and sometimes extensive haemorrhage and necrosis. Between these extremes, tumours of intermediate morphology, mitotic activity, and growth rate are found. This system, therefore, provides a graded series of neoplasms derived from a single cell type in which tumours can be grouped into three main classes according to their histological differentiation and growth rate. The biological stability of these tumours has been well tested and it provides a highly reliable system for quantitative analysis of tumour enzyme activity.

\section{Enzymes and Differentiation of Hepatomas}

In recent years rapid advances have been made in the identification of critical or key enzymes in a number of pathways of intermediary metabolism. Assay of these key enzymes under optimal biochemical conditions reveals the functional phenotype of the cell and reflects its genomic activity at that time. Assessment of the responsiveness of these key enzymes to normal regulatory controls can also be made by the performance of various nutritional and hormonal manipulations (Weber and Lea, 1967).

A systematic approach of this kind applied to the spectrum of hepatomas has revealed a clear alteration in the pattern of normal hepatic enzyme activity which can be correlated with the degree of structural differentiation and growth rate of the tumours. The principal quantitative changes in the key pathway enzymes of intermediary metabolism have been extensively studied and reviewed by Weber and his associates (Weber, Henry, Wagle, and Wagle, 1964; Weber, 1966; Weber and Lea, 1966, 1967; Weber, Queener, and Ferdinandus, 1971; Weber, 1972; Weber, Ferdinandus, Queener, Dunaway, and Trahan, 1972). A summary only of the principal findings is given here and their papers should be consulted for the original sources of the data on which it is based. In all of the results described the normal adult rat liver serves as the standard with which the hepatoma data are compared.

ENZYMES OF CARBOHYDRATE METABOLISM Progressive loss of structural differentiation in hepatomas is associated with characteristic but opposing changes in the activity of key enzymes of the synthetic and catabolic pathways of carbohydrate metabolism. Thus, as tumours become less well differentiated there is a proportionate reduction in the activity of key gluconeogenic enzymes (table I).
The changes in enzyme activity correlate closely with the overall reduction in rate of gluconeogenesis as measured by the conversion of isotopically labelled pyruvate into lactate. Moreover, alteration in the normal regulation of gluconeogenic enzymes is observed and the pronounced increase in enzyme activity which normally follows glucocorticoid administration is greatly reduced in well differentiated hepatomas whereas in poorly differentiated tumours it is completely absent. Consistent with these findings are the low levels of glycogen in many hepatomas whereas activity of phosphoglucomutase is greatly diminished.

By contrast, the activity of key glycolytic enzymes increases in parallel with the decrease in tumour differentiation (table I), and the increased rate of glycolysis measured by the production of lactate in tumours corresponds with the increased levels of glycolytic enzymes. However, the rate of glycolysis in some well differentiated ('minimal deviation') tumours is in the same range or lower than that of normal liver, refuting the long-held view that all cancers necessarily exhibit an increased rate of glycolysis (Warburg, 1930).

\begin{tabular}{|c|c|}
\hline Enzyme & $\begin{array}{l}\text { Alteration with Loss of } \\
\text { Structural } \\
\text { Differentiation }\end{array}$ \\
\hline $\begin{array}{l}\text { Gluconeogenesis } \\
\text { Glucose-6-phosphatase } \\
\text { Fructose-1,6-diphosphatase } \\
\text { Phosphoenolpyruvate carboxykinase } \\
\text { Pyruvate carboxylase }\end{array}$ & Decrease \\
\hline $\begin{array}{l}\text { Glycolysis } \\
\text { Hexocinase } \\
\text { Phosphofructokinase } \\
\text { Pyruvate kinase }\end{array}$ & Increase \\
\hline
\end{tabular}

Table I Alteration in key enzymes of carbohydrate metabolism in hepatomas

ENZYMES OF PROTEIN METABOLISM

A progressive imbalance in the metabolism of proteins is observed in hepatomas which correlates with the degree of tumour differentiation. Thus it has been found that as tumour differentiation decreases there is a corresponding increase in the biosynthesis of proteins as measured by the incorporation of ${ }^{14} \mathrm{C}$ labelled amino acids.

By contrast, catabolism of amino acids is decreased as tumours become progressively less well differentiated and the enzymes catalysing the degradation of amino acids show similar reductions in activity (table II). Furthermore, the normal regulation of certain of these enzymes is greatly modified. Thus, the normal increase in hepatic levels of threonine dehydrase and serine dehydratase induced 


\begin{tabular}{|c|c|}
\hline Enzyme & $\begin{array}{l}\text { Alteration with Loss of } \\
\text { Structural Differentiation }\end{array}$ \\
\hline $\begin{array}{l}\text { Serine dehydratase } \\
\text { Threonine dehydrase } \\
\text { Tryptophan pyrrolase } \\
\text { Serotonin deaminase } \\
\text { Hydroxytryptophan decarboxylase } \\
\text { Aspartate aminotransferase } \\
\text { Glutamate dehydrogenase } \\
\text { Alanine aminotransferase } \\
\text { Tyrosine transaminase }\end{array}$ & Decrease \\
\hline
\end{tabular}

Table II Alteration in enzymes of amino acid catabolism in hepatomas

by high protein diet fails to occur in many hepatomas; and, whereas injection of tryptophan results in increased tryptophan pyrrolase activity in normal liver, this response is absent in the hepatomas. In addition, more subtle differences in the normal regulation of serine dehydratase and tryptophan pyrrolase activity are revealed by their differential sensitivity to the effects of actinomycin D following enzyme induction (Pitot, Peraino, Lamar, and Kennan, 1965).

\section{ENZYMES OF NUCLEIC ACID METABOLISM} A positive correlation is found with the progressive loss of tumour differentiation for a number of key enzymes in nucleic acid metabolism. Increase in activity of enzymes involved in the biosynthetic pathways of pyrimidine and DNA metabolism occurs as hepatomas become progressively less well differentiated (table III). Thymidine utilization studies have confirmed that concurrent with the increase in enzyme activity there is a parallel increase in the rate of DNA synthesis.

Degradation of pyrimidine, however, decreases in proportion to the extent of tumour dedifferentiation and the key rate-limiting enzyme in this pathway, dihydrouracil dehydrogenase, shows a corresponding reduction in activity.

\begin{tabular}{ll}
\hline Enzyme & $\begin{array}{l}\text { Alteration with Loss of } \\
\text { Structural }\end{array}$ \\
\hline $\begin{array}{l}\text { Anabolic } \\
\text { Thymidine kinase } \\
\text { Thymidylic kinase } \\
\text { Thymidylic synthase }\end{array}$ \\
$\begin{array}{l}\text { Deoxycytidylic deaminase } \\
\text { Carbamylaspartate transferase } \\
\text { Dihydroorotase } \\
\text { Ribonucleotide reductase } \\
\text { Deoxyribonucleic acid polymerase }\end{array}$ \\
$\begin{array}{l}\text { Carabolic } \\
\text { Dihydrouracil dehydrogenase }\end{array}$ \\
\hline
\end{tabular}

Table III Alteration in enzymes of pyrimidine and deoxyribonucleic acid metabolism in hepatomas
ENZYMES OF ORNITHINE METABOLISM

It has also been demonstrated recently that a progressive imbalance in ornithine metabolism occurs in hepatomas (Williams-Ashman, Coppoc, and Weber, 1972). It would appear that with progressive loss of tumour differentiation the balance of ornithine utilization between the urea cycle and polyamine synthesis alters in favour of increased biosynthesis of polyamines. Corresponding changes occur in the key pathway enzymes involved: activity of ornithine carbamyl transferase, which channels ornithine into the urea cycle, shows a progressive reduction with declining tumour differentiation whereas ornithine decarboxylase, which diverts ornithine into biosynthesis of polyamines, was increased. The biological significance of these changes may lie in the decline in utilization of carbamyl phosphate and aspartate for urea cycle metabolism thereby releasing these precursors for biosynthesis of purines and pyrimidines.

Thus, in this graded series of hepatomas a clear alteration in the pattern of activity of many of the key enzymes of intermediary metabolism has been established. The changes in enzyme activity are closely correlated with the overall changes in the rate of metabolism in the pathways concerned and are directly related to the degree of histological differentiation of tumours and their growth rate. The significance of these changes will be discussed later.

\section{Isozymes in Hepatomas}

For some time it has been recognized that many tissue enzymes exist not as pure protein species but in multiple molecular forms or isozymes (Markert and Møller, 1959). The various isozymic forms of an enzyme may differ in a number of physical and chemical properties which are thought to have great functional significance (Cahn, Kaplan, Levine, and Zwilling, 1962). In recent years it has become apparent that many neoplastic tissues may undergo marked shifts in their isozymic content (Criss, 1971). In certain instances this has been attributed to significant alterations in the metabolic characteristics of the tumour tissues (Goldman, Kaplan, and Hall, 1964; Bird and Mainzer, 1972). Clearly any systematic analysis of hepatoma enzymes must consider the isozyme profile of key enzymes.

Indeed, studies of hepatoma enzymes have revealed that many tumours possess high activities of isozymes that are normally low or absent in fully differentiated hepatocytes, whereas other isozymes, usually those which are responsive to regulatory hormones or metabolites, are low or absent (Otani and Morris, 1965; Adelman, Morris, and Wein- 


\begin{tabular}{|c|c|c|c|c|}
\hline \multirow{2}{*}{$\begin{array}{l}\text { Enzyme } \\
\text { Hexokinase }\end{array}$} & \multicolumn{2}{|c|}{ Isozymes in Normal Tissues } & \multicolumn{2}{|c|}{ Alteration in Hepatomas } \\
\hline & $\begin{array}{l}\text { I, II, III } \\
\text { IV }\end{array}$ & $\begin{array}{l}\text { Non-hepatic tissues; fetal liver } \\
\text { Adult liver }\end{array}$ & $\begin{array}{l}\text { IV } \\
\text { I, II, III }\end{array}$ & $\begin{array}{l}\text { Decrease } \\
\text { Increase }\end{array}$ \\
\hline Aldolase & $\begin{array}{l}\mathbf{A} \\
\mathbf{B}\end{array}$ & $\begin{array}{l}\text { Muscle; fetal liver } \\
\text { Adult liver }\end{array}$ & $\begin{array}{l}\mathbf{B} \\
\mathbf{A}\end{array}$ & $\begin{array}{l}\text { Decrease } \\
\text { Increase }\end{array}$ \\
\hline Pyruvate kinase & $\begin{array}{l}\text { I, III } \\
\text { II } \\
\text { II, III }\end{array}$ & $\begin{array}{l}\text { Adult liver } \\
\text { Muscle } \\
\text { Fetal liver }\end{array}$ & $\begin{array}{l}\text { I } \\
\text { II, III }\end{array}$ & $\begin{array}{l}\text { Decrease } \\
\text { Increase }\end{array}$ \\
\hline Fructose-1,6-diphosphatase & $\begin{array}{l}\mathbf{L} \\
\mathbf{M}\end{array}$ & $\begin{array}{l}\text { Adult liver, kidney } \\
\text { Muscle }\end{array}$ & $\mathbf{M}$ & Increase \\
\hline Glutaminase & \multicolumn{2}{|c|}{$\begin{array}{l}\text { Phosphate-dependent } \\
\text { Phosphate-independent- } \\
1 \text { Liver-specific } \\
2 \text { Kidney-specific; fetal liver }\end{array}$} & \multicolumn{2}{|c|}{$\begin{array}{l}\text { Phosphate-independent- } \\
\text { Kidney-specific } \\
\text { Increase }\end{array}$} \\
\hline DNA polymerase & $\begin{array}{l}\text { I, II } \\
\text { III }\end{array}$ & $\begin{array}{l}\text { Use denatured DNA; fetal liver } \\
\text { Uses native DNA; adult liver }\end{array}$ & $\begin{array}{l}\text { III } \\
\text { II }\end{array}$ & $\begin{array}{l}\text { Decrease } \\
\text { Increase }\end{array}$ \\
\hline Aspartate aminotransferase & \multicolumn{2}{|c|}{$\begin{array}{l}\text { Mitochondrial } \\
\text { Cytoplasmic }\end{array}$} & Cytoplas & Increase \\
\hline Adenylate kinase & $\begin{array}{l}\text { II } \\
\text { III }\end{array}$ & $\begin{array}{l}\text { Muscle; heart; brain; lung } \\
\text { Adult liver; kidney }\end{array}$ & III & Decrease \\
\hline
\end{tabular}

Table IV Isozyme changes in some hepatoma enzymes

house, 1967; Farina, Adelman, Lo, Morris, and Weinhouse, 1968; Linder-Horowitz, Knox, and Morris, 1969; Ove, Brown, and Laszlo, 1969; Sato and Tsuiki, 1969; Shatton, Morris, and Weinhouse, 1969; Criss, Litwack, Morris, and Weinhouse, 1970; Weinhouse, 1971; Walker and Potter, 1972). The principal changes described for some of these enzymes are summarized in table IV. A striking feature in many hepatomas has been the apparent reactivation of isozymes characteristic of fetal or neonatal liver; less commonly isozymes of other organs have been found. Such alterations appear to be related to the loss of tumour differentiation and are most marked in poorly differentiated, rapidly growing hepatomas. The resemblance of the isozyme profile of poorly differentiated hepatomas to that of the fetal liver is consistent with the development of other fetal cell characteristics, notably the synthesis of alpha-fetal serum protein and other fetal proteins (Stanislawski-Birencwajg, Uriel, and Grabar, 1967). It seems certain that such qualitative changes in enzyme content must have significant effects on the metabolic characteristics of tumours.

\section{Discussion}

It is readily apparent, therefore, from this brief summary of the enzyme activity of hepatomas that loss of structural differentiation in these tumours is associated with progressive alteration in their enzymic properties. These changes are characterized in part by quantitative shifts in the activity of opposing groups of key enzymes in several of the main pathways of intermediary metabolism together with a gradual decline in response of several of these enzyme-forming systems to normal regulatory controls. Study of the isozyme profile of hepatomas has revealed additional qualitative changes in enzyme activity whereby the levels of isozymes normally responsive to regulatory controls are reduced and they have been replaced by isozymes which are more characteristic of the fetal or neonatal liver.

Although the enzymic fluctuations in hepatomas can be correlated also with the growth rate of the tumours, the quantitative shifts in enzyme activity appear to have some specificity for the neoplastic form of proliferation. Thus similar patterns of enzyme activity are not found in the rapidly regenerating liver following partial hepatectomy or in the rapidly growing liver of the neonatal rat. In these circumstances it is possible for liver tissues to undergo rapid proliferation at rates comparable to that of the growth of many hepatomas without severe reduction or loss of groups of enzymes or the failure of operation of whole metabolic pathways (Weber, 1966; Weber et al, 1971; Weber, 1972). Therefore, whilst it may be reasonable to ascribe some of the enzymicand metabolic changes observed in hepatomas simply to increased rates of cellular replication, it would seem that certain of these at least must have a more fundamental basis in the nature of the neoplastic state.

Whether or not the changes demonstrated in the graded series of hepatomas can be regarded as a general feature of all classes of neoplasm still remains to be established. At present systematic studies of this kind have not been performed with other tumour systems although sporadic attempts have been made to correlate the activity of single or random groups of enzymes with the structural differentiation of certain experimental and human 
tumours. Thus, Knox, Horowitz, and Friedell (1969) found in a heterogeneous group of transplantable and primary rat tumours that the level of glutaminase activity increased as the histological differentiation of tumours decreased. A similar correlation was subsequently found for this enzyme with a histologically graded series of rat mammary tumours of spontaneous origin or induced experimentally with chemicals or radiations (Knox, Linder, and Friedell, 1970). In man, the activity of beta-glucuronidase was found to increase in parallel with decreasing differentiation of cerebral astrocytomas (Allen, 1961 and 1962); and, in histochemical studies of human colonic carcinomas, Wattenberg (1959) found that as tumour differentiation decreased activity of TPN and DPN diaphorase increased. By contrast, in the same tumours activity of succinic and alpha-glycerophosphate dehydrogenase was reduced. In studies of human prostate cancer, some workers have shown by quantitative histochemical techniques that the level of acid phosphatase activity is reduced as tumour differentiation decreases (Parkin, Bylsma, Torre, Drew, and Madden, 1964). Other histochemical studies of human cancers have revealed somewhat conflicting results which may be attributed in part to the methodology employed (Dawson, 1967).

The measurement of single or random groups of enzymes provides little information regarding their functional role in the metabolism of a tumour. The true significance of fluctuations in enzyme activity can only be assessed when it is possible to relate them to the activities of other cellular enzymes and particularly to those which are components of the same metabolic pathways or utilize common substrates (Shonk and Boxer, 1967). There is obviously a need, therefore, for systematic analysis of other tumour systems to determine the generality of the hepatoma findings.

Several attempts have been made to formulate the hepatoma phenotype on a rational biochemical basis. To Weber the enzyme and metabolic activity of hepatomas constitutes a definitive pattern at the molecular level which can be explained only in terms of ordered alterations in gene expression. These opinions have been incorporated in the 'molecular correlation concept of neoplasia' (Weber, 1966; Weber and Lea, 1966 and 1967; Weber, 1972). Here it is postulated that metabolic homeostasis in tissues is normally maintained by the antagonistic activity of key enzymes regulating the synthetic and catabolic pathways of intermediary metabolism. The key enzymes of each pathway are envisaged as forming separate functional genic units whose coordinated activity regulates the overall balance of metabolism in tissues. In hepatomas it is proposed that genetically determined alterations in the expression of whole genic units produce changes in the activity of groups of key enzymes with corresponding effects on the balance of metabolism in the pathways concerned. The gradually developing imbalance in the enzyme and metabolic activity of hepatomas can certainly be explained on this basis, although the precise nature of the genetic alterations has not been defined.

A different formulation of a somewhat similar interpretation was stimulated by the apparent reactivation in hepatomas of enzymes characteristic of the fetal or neonatal liver. Initially, it was suggested that synthesis of fetal enzymes was the result of the derepression of genes for fetal proteins (Schapira, Dreyfus, and Schapira, 1963; Schapira, Reuber, and Hatzfeld, 1970). This concept, however, has been amplified by Potter in what he has termed 'oncogeny as blocked ontogeny' (Potter, 1969; Walker and Potter, 1972). It was observed that during normal 'ontogeny' in liver the isozymes of the fetal and neonatal rat are gradually replaced by those characteristic of the adult animal. However, the potential for synthesis of certain fetal isozymes is retained by the adult organ and when fully mature hepatocytes are stimulated to undergo cell division they cease production of some of the adult isozymes and revert to production of fetal isozymes. This process has been termed 're-ontogeny'. This phenomenon was related to the processes of cell division irrespective of the initiating cause and the same degree of enzyme dedifferentiation was observed in the regenerating liver after partial hepatectomy as in the nodular precancerous liver following carcinogen administration. However, in the regenerating liver it appears that the process is controlled and the newly formed hepatocytes undergo differentiation to generate fully mature liver cells with a normal complement of adult isozymes. Similarly, in the precancerous liver it is probable that many hyperplastic cells may undergo complete histological and enzymic differentiation but the 'blocked ontogeny' hypothesis postulates that some cells are unable to complete this process and develop into clones of hepatoma cells. Hepatomas of diverse enzymic phenotype would thus be produced depending upon the combination of blocks and the stages at which blockages of differentiation occur.

Thus both interpretations of the enzyme and metabolic patterns of hepatomas focus attention on alterations in the genomic properties of tumour cells. Whilst they offer a rational explanation for the great diversity of enzymic phenotypes observed in hepatomas neither explains whether these changes should be regarded as concomitant or essential to the phenomenon of neoplastic transformation. The 
solution to this vital question still remains to be elucidated.

\section{Summary}

Although numerous studies of tumour enzymes have been made in the past it has been possible only since the introduction of the transplantable series of rat hepatomas to evaluate the significance of these changes in terms of the structural differentiation of tumours. Systematic analysis of the hepatomas has revealed a characteritic pattern of change in opposing groups of key enzymes in several pathways of intermediary metabolism. The net outcome of this change is that with decreasing tumour differentiation parallel reductions are observed in the synthetic pathways of carbohydrate metabolism and in the catabolic pathways of protein and nucleic acid metabolism; in ornithine metabolism preferential channelling of ornithine into polyamine biosynthesis occurs. Whilst these enzymic and metabolic changes correlate also with the growth rate of hepatomas, they cannot be attributed solely to the increased rate of cellular proliferation since similar patterns of enzyme activity are not reproduced in other nonneoplastic proliferative conditions of the liver. Significant changes in the isozyme content of hepatomas have also been demonstrated as tumours become progressively less well differentiated and frequently these are associated with the reactivation of isozymes characteristic of the fetal or neonatal liver. Interpretations of the enzymic and metabolic changes in hepatomas have focused attention on possible alterations in the genomic activity of tumour cells, although it is still not clear whether these should be regarded as concomitant or essential to the process of neoplastic transformation.

Comparable studies of the enzymic and metabolic properties of other tumour systems have not yet been made and there is a clear need for these to establish the significance of the hepatoma findings for cancer in general.

References

Adelman, R. C., Morris, H. P., and Weinhouse, S. (1967). Fructokinase, triokinase, and aldolases in liver tumors of the rat. Cancer Res., 27, 2408-2413.

Aisenberg, A. C. (1961). The Glycolysis and Respiration of Tumours. Academic Press, New York and London.

Allen, N. (1961). Beta-glucuronidase activities in tumors of the nervous system. Neurology (Minneap.), 11, 578-596.

Allen, N. (1962). Distribution patterns of three enzymes in tumors of the nervous system. In IV International Congress on Neuropathology: Proceedings, vol. 1, pp. 104-109. Thieme, Stuttgart.

Bird, C. C., and Mainzer, K. (1972). Leukaemia evoked with 7,8,12trimethylbenz(a)anthracene in rat. III. Changes in lymphoid tissues. Brit. J. Cancer, 26, 373-379.

Busch, H., and Starbuck, W. C. (1964). Biochemistry of cancer. Ann. Rev. Biochem., 33, 519-570.

Cahn, R. D., Kaplan, N. O., Levine, L., and Zwilling, E. (1962). Nature and development of lactic dehydrogenases. Science, 136, 962-969.
Criss, W. E. (1971). A review of isozymes in cancer. Cancer Res., 31, 1523-1542.

Criss, W. E. Litwack, G., Morris, H. P., and Weinhouse, S. (1970). Adenosine triphosphate: adenosine monophosphate phosphotransferase isozymes in rat liver and hepatomas. Cancer Res., 30, 370-375.

Dawson, I. M. P. (1967). Enzyme systems at cellular level. Progr. clinical Cancer, 3, 31-50.

Farber, E. (1968). On the concept of minimum deviation in the study of the biochemistry of cancer (L etter). Cancer Res., 28, 1210-1211.

Farina, F. A., Adelman, R. C., Lo, C. H., Morris, H. P., and Weinhouse, S. (1968). Metabolic regulation and enzyme alterations in the Morris hepatomas. Cancer Res., 28, 1897-1900.

Goldman, R. D., Kaplan, N. O., and Hall, T. C. (1964). Lactic dehydrogenase in human neoplastic tissues. Cancer Res., 24, 389-399.

Greenstein, J. P. (1954). Biochemistry of Cancer, 2nd ed. Academic Press, New York.

Greenstein, J. P. (1956). Some biochemical characteristics of morphologically separable cancers. Cancer Res., 16, 641-653.

Knox, W. E. (1967). The enzymic pattern of neoplastic tissue. Advanc. Cancer Res., 10, 117-161.

Knox, W. E., Horowitz, M. L., and Friedell, G. H. (1969). The proportionality of glutaminase content to growth rate and morphology of rat neoplasms. Cancer Res., 29, 669-680.

Knox, W. E., Linder, M., and Friedell, G. H. (1970). A series of transplantable rat mammary tumours with graded differentiation, growth rate and glutaminase content. Cancer Res., 30, 283-287.

Linder-Horowitz, M., Knox, W. E., and Morris, H. P. (1969). Glutaminase activities and growth rates of rat hepatomas. Cancer Res., 29, 1195-1199.

Markert, C. L., and Moller, F. (1959). Multiple forms of enzymes. tissue, ontogenetic and species specific patterns. Proc. nat. Acad. Sci. (Wash.), 45, 753-763.

Miller, E. C., and Miller, J. A. (1947). The presence and significance of bound aminoazo dyes in the livers of rats fed p-dimethylaminoazobenzene. Cancer Res., 7, 468-480.

Morris, H. P. (1963). Some growth, morphological, and biochemical characteristics of hepatoma 5123 and other new transplantable hepatomas. Progr. exp. Tumor Res. (Basel), 3, 370-411.

Morris, H. P. (1965). Studies on the development, biochemistry and biology of experimental hepatomas. Advanc. Cancer Res., 9, 227-302.

Morris, H. P., and Wagner, B. P. (1968). Induction and transplantation of rat hepatomas with different growth rate (including 'minimal deviation' hepatomas). Meth. Cancer Res., 4, 125-152.

Otani, T. T., and Morris, H. P. (1965). Isozymes of glutamic-oxaloacetic transaminase in some rat hepatomas. Advanc. Enzyme Reg., 3, 325-334.

Ove, P., Brown, O. E., and Laszlo, J. (1969). Separation of DNA polymerase from rat liver and hepatomas. Cancer Res., 29, 1562-1567.

Parkin, L., Bylsma, G., Torre, A. V., Drew, D., and Madden, R. J. (1964). Acid phosphatase in carcinoma of the prostate in man. J. Histochem. Cytochem., 12, 288-292.

Pitot, H. C. (1966). Some biochemical aspects of malignancy. Ann. Rev. Biochem., 35, 335-368.

Pitot, H. C., Peraino, C., Lamar, C., Jr., and Kennan, A. L. (1965). Template stability of some enzymes in rat liver and hepatoma. Proc. nat. Acad. Sci. (Wash.), 54, 845-851.

Potter, V. R. (1958). The biochemical approach to the cancer problem. Fed. Proc., 17, 691-697.

Potter, V. R. (1969). Recent trends in cancer biochemistry: the importance of studies on fetal tissue. Canad. Cancer Confr., 8, 9-30.

Sato, K., and Tsuiki, S. (1969). Fructose-1,6-diphosphatase of rat tissues and transplantable rat hepatomas. Arch. Biochem., 129, 173-180.

Schapira, F., Dreyfus, J. C., and Schapira, G. (1963). Anomaly of aldolase in primary liver cancer. Nature (Lond.), 200, 995-997.

Schapira, F., Reuber, M. D., and Hatzfeld, A. (1970). Resurgence of two fetal-type of aldolases (A and $C$ ) in some fast-growing hepatomas. Biochem. biophys. Res. Commun., 40, 321-327.

Shatton, J. B., Morris, H. P., and Weinhouse, S. (1969). Kinetic, electrophoretic and chromatographic studies on glucose-ATP phosphotransferases in rat hepatomas. Cancer Res., 29, 1161. 1172. 
Shonk, C. E., and Boxer, G. E. (1967). Enzymology of solid human tumors. Meth. Cancer Res., 2, 579-661.

Stanislawski-Birencwajg, M., Uriel, J., and Grabar, P. (1967). Association of embryonic antigens with experimentally induced hepatic lesions in the rat. Cancer Res., 27, 1990-1997.

Walker, P. R., and Potter, V. R. (1972). Isozyme studies on adult, regenerating, precancerous and developing liver in relation to findings in hepatomas. Advanc. Enzyme Reg., 10, 339-364.

Warburg, O. (1930). The Metabolism of Tumours. Constable, London.

Wattenberg, L. W. (1959). A histochemical study of five oxidative enzymes in carcinoma of the large intestine in man. Amer. $J$. Path., 35, 113-137.

Weber, G. (1966). The molecular correlation concept: studies on the metabolic pattern of hepatomas. Gann Monogr. Cancer Res., 1, 151-178.

Weber, G. (1972). Molecular correlation concept: ordered pattern of gene expression in neoplasia. Gann. Monogr. Cancer. Res., 13, 47-77.

Weber, G., Ferdinandus, J. A., Queener, S. F., Dunaway, G. A., and Trahan, L. J. P. (1972). Metabolic imbalance in carbohydrate, pyrimidine and ornithine utilization. Advanc. Enzyme Reg., 10, 39-62.

Weber, G., Henry, M. C., Wagle, S. R., and Wagle, D. S. (1964) Correlation of enzyme activities and metabolic pathways with growth rate of hepatomas. Advanc. Enzyme Reg., 2, 335-346.

Weber, G., and Lea, M. A. (1966). The molecular correlation concept of neoplasia. Advanc. Enzyme Reg., 4, 115-145.

Weber, G., and Lea, M. A. (1967). The molecular correlation concept an experimental and conceptual method in cancer research. Meth. Cancer Res., 2, 523-578.

Weber, G., Queener, S. F., and Ferdinandus, J. A. (1971). Control of gene expression in carbohydrate, pyrimidine and DNA metabolism. Advanc. Enzyme Reg., 9, 63-95.

Weinhouse, S. (1971). Isozymes in cancer. Cancer Res., 31, 1166-1167. Wenner, C. E. (1967). Progress in tumor enzymology. Advanc. Enzymol., 29, 321-390.

Williams-Ashman, H. G., Coppoc, G. L., and Weber, G. (1972) Imbalance in ornithine metabolism in hepatomas of different growth rates as expressed in formation of putrescine, spermidine and spermine. Cancer Res., 32, 1924-1932. 